Bryn Mawr College

Scholarship, Research, and Creative Work at Bryn Mawr

College

Psychology Faculty Research and Scholarship

Psychology

2005

\title{
Adolescents' Behavior in the Presence of Interparental Hostility: Developmental and Emotion Regulatory Influences
}

Marc S. Schulz

Bryn Mawr College, mschulz@brynmawr.edu

Robert J. Waldinger

Stuart T. Hauser

Joseph P. Allen

Let us know how access to this document benefits you.

Follow this and additional works at: http://repository.brynmawr.edu/psych_pubs

Part of the Psychology Commons

\section{Custom Citation}

Schulz, Marc S., Robert J. Waldinger, Stuart T. Hauser, and Joseph P. Allen. "Adolescents' Behavior in the Presence of Interparental Hostility: Developmental and Emotion Regulatory Influences." Development and Psychopathology 17 (2005): 489-507, doi:10.1017/ S0954579405050236.

This paper is posted at Scholarship, Research, and Creative Work at Bryn Mawr College. http://repository.brynmawr.edu/psych_pubs/6

For more information, please contact repository@brynmawr.edu. 


\title{
Adolescents' behavior in the presence of interparental hostility: Developmental and emotion regulatory influences
}

\author{
MARC S. SCHULZ, ${ }^{a}$ ROBERT J. WALDINGER,${ }^{b}$ STUART T. HAUSER,${ }^{b}$ \\ AND JOSEPH P. ALLEN ${ }^{c}$ \\ ${ }^{a}$ Bryn Mawr College; ${ }^{b} J u d g e$ Baker Children's Center; and ${ }^{c}$ University of Virginia
}

\begin{abstract}
Within-family covariation between interparental hostility and adolescent behavior across three interactions over a 2-year period was explored in a sample that included 37 typical adolescents and 35 adolescents recently hospitalized for psychiatric difficulties. More interparental hostility across the three interactions was associated with more adolescent hostility and more positive engagement (at a trend level) regardless of psychiatric background. Parent-to-child hostility in each interaction mediated the link for adolescent hostility but not for positive adolescent engagement. Emotion regulation capacities and age were linked to variability in adolescents' behavior in the presence of interparental conflict. In interactions with more interparental hostility, adolescents with greater capacity to tolerate negative affect were more likely to show increased positive engagement, and adolescents who were better able to modulate their emotional expression were less likely to show increased hostility. Covariation between interparental and adolescent hostility across the three family interactions decreased as the adolescent aged. These findings are consistent with the theory that exposure to interparental hostility is emotionally disequilibrating, and that adolescent responses may reflect differences in emotion regulation and other developmentally based capacities. Gender and variations across families in overall levels of hostile parenting were also linked with adolescent behavior in the presence of interparental hostility.
\end{abstract}

Researchers have found consistent correlational links between exposure to marital conflict and problematic functioning in children, yet the specific mechanisms responsible for these connections remain unclear (Davies \& Cummings, 1994; Grych \& Fincham, 1990). Much of the recent theoretical and empirical inquiry about mechanisms has focused on the idea that conflict between parents is emotionally disequilibrating for children (Crockenberg \& Forgays, 1996; Crockenberg \&

This research was supported, in part, by a grant from the National Institute of Mental Health (RO1 MH 4493). The authors thank J. Heidi Gralinski-Bakker and Rebecca Billings for their valuable assistance with this research.

Address correspondence and reprint requests to: Marc S. Schulz, Department of Psychology, Bryn Mawr College, 101 North Merion Avenue, Bryn Mawr, PA 19010.
Langrock, 2001; Davies \& Cummings, 1994; Davies \& Forman, 2002). Closely observing children's immediate emotional and behavioral responses to interparental conflict is critical for learning more about how couples' conflict and child functioning may be linked (Cummings, 1987; Davies \& Cummings, 1994). However, much of the work in this area has relied on analog experimental designs that expose children to simulated conflict between adult strangers (e.g., Davies, Myers, Cummings, \& Heindel, 1999), a strategy that may not yield information that accurately reflects children's responses to real conflict between their actual parents.

Despite a rich existing literature emphasizing the importance of observing family processes over time (e.g., Patterson and Reid, 1984), relatively few investigators have at- 
tempted to observe children's behavior in the presence of their parents' discord during a series of family interactions. In most studies, questions are limited to traditional betweensubjects comparisons at one point in time between children in families with greater marital discord and children in families with less marital discord. These studies indicate that adolescents in families with more interparental conflict are more likely to exhibit aggressive behavior than those children from families with less interparental conflict (Amato \& Keith, 1991). Because most studies to date have not observed interactions from the same family across multiple time points, they have not been able to capture variation in each child's behavior across occasions that may be a function of variation in parents' marital conflict or hostility on these occasions. This type of within-family covariation (between children's behavior and interparental conflict) is predicted by most process-oriented theories of the effects of marital conflict on children (e.g., Crockenberg \& Langrock, 2001; Davies \& Cummings, 1994). Another limitation of single point in time studies is their inability to directly address questions about how developmental factors might influence children's responses to interparental conflict. However, as Fincham and Grych (2001) recently observed, "Virtually all the research in ... [this] field involves data gathered at a single point in time and thus provides us a snapshot of the phenomena we study (p.448)."

In this study, we observed family interactions at three time points (when adolescents were 14,15 , and 16) so that we could examine how adolescents' behavior in their families might change as a function of the level of interparental hostility present in each interaction, and whether there were developmental trends in these within-family linkages. By focusing on patterns of within-family covariation of interparental hostility and adolescent behavior across time we are following in the tradition of "person-centered" research increasingly emphasized by researchers in developmental and related fields (e.g., Cairns, Bergman, \& Kagan, 1998; Magnusson, 1998; Nesselroade, 2001). Two key obstacles have hindered the application of this approach to the study of fam- ily relationship patterns across time. The first is the practical difficulty of collecting family observations across time, and the second is the complexity of the data analytic issues involved. Multilevel data analytic procedures, such as hierarchical linear modeling (HLM), have provided a powerful tool to enable researchers to combine individual and group-level analyses. Trends within families across multiple occasions can be identified, and differences in the pattern of these trends across families can be linked to variables that distinguish these families.

In this study, we investigated two behavioral responses, hostility and relationshipfacilitating behaviors, that adolescents may employ to regain a sense of emotional security in the face of interparental discord (Davies \& Cummings, 1994, 1998). In addition to developmental influences, we explored how stable person-based and family-based differences might shape adolescents' behavior in the presence of interparental hostility. Although previous research indicates that there is considerable variability in children's responses to interparental conflict (Davies \& Cummings, 1994; Grych \& Fincham, 1990), much remains to be understood about the factors that moderate or shape these varied responses. In this study, we focused particularly on the moderating influence of age at the time of each interaction and two emotion regulatory capacities that differ across adolescents: the ability to tolerate the experience of emotional distress, and the ability to modulate one's emotional expression and responses when negatively aroused. We also explored whether variation in adolescents' behavior in the presence of interparental hostility was related to their gender and to the typical affective quality of the parenting they received. Previous research suggests that links between marital conflict and children's behavior problems are stronger in clinical samples than in community-based samples (Emery \& O'Leary, 1984; Jouriles, Bourg, \& Farris, 1991; Reid \& Crisafulli, 1990). We explored this possibility by examining family processes in a sample that incorporates both typical adolescents and adolescents with a recent history of psychiatric difficulties. 


\section{Children's Responses to Marital Conflict}

Children do not respond uniformly to discord between adults. When exposed to simulated interadult conflicts in the laboratory, children manifest a wide range of reactions, including increased aggressiveness (Cummings, Vogel, Cummings, \& El-Sheikh, 1989), increased physiological reactivity (El-Sheikh, Harger, \& Whitson, 2001; Katz \& Gottman, 1995, 1997), and more negative emotion (Cummings et al., 1989; Cummings, Iannotti, \& Zahn-Waxler, 1985). Laboratory research also demonstrates that children show greater reactivity to conflict stimuli that are of stronger intensity (Cummings et al., 1985, 1989; Cummings, Simpson, \& Wilson, 1993; Grych \& Fincham, 1993; Davies \& Cummings, 1998).

Similar conclusions have been reached in observational or questionnaire-based studies of actual family interactions (e.g., Easterbrooks, Cummings, \& Emde, 1994; Greene \& Anderson, 1999). Davis, Hops, Alpert, and Sheeber (1998) carefully tracked children's responses to parental conflict in family interactions and found that aggressive behavior by the child was the most likely response to interparental conflict. Other research has provided evidence that some children may attempt to become "peacekeepers" in the presence of parental conflict by engaging in facilitative or supportive family behaviors (Emery, 1982; Jenkins, Smith, \& Graham, 1989; Kerig, 2001; Wallerstein \& Blakeslee, 1989).

Children's varied responses to adult conflict may reflect differences in the perceived meaning of the conflict to the child and differences in the strategies that the child employs to cope with internal distress or family tensions. A leading theoretical framework, the emotional security hypothesis (Davies \& Cummings, 1994), suggests that interparental conflict makes children feel less emotionally secure in their families and that children's responses are shaped by desires to reduce exposure to further conflict and to experience less vulnerability and more security. Two common types of child responses to quarreling parents (aggressive and facilitative behaviors) can be viewed as different strategies to reestablish the child's sense of security and control. A critical task for researchers is to identify the factors that lead a child to favor one of these strategies over the other.

\section{Adolescence and Responses to Marital Conflict}

Coping strategies evolve as children develop (Schulz \& Lazarus, in press). Empirical work suggests that advances in cognitive sophistication are linked to an expanded range of coping skills (Grych \& Cardoza-Fernandes, 2001). Compared to younger children, adolescents have greater access to emotion-focused coping strategies, such as self-calming. However, investigators (e.g., Cummings, Ballard, \& ElSheikh, 1991; Davies, Myers, \& Cummings, 1996) have found that adolescents are more likely than younger children to react to interparental discord with strategies that attempt to alter the situation (i.e., problem-focused coping). Specifically, adolescents are more likely to endorse intervening in their parents' arguments. As Kerig (2001) points out, cognitive development may actually increase adolescents' tendency to intervene in parental arguments because they are able to do so more effectively than younger children.

Interparental conflict may have unique meaning and implications during adolescence because of the central relational challenges that adolescents face. Adolescence is permeated by a dialectic between strivings for autonomy from parents and a desire to remain close to them (Allen, Hauser, Bell, \& O'Connor, 1994; Allen, Kuperminc, \& Moore, 1997). The presence of discord between parents may stimulate discomfort for adolescents, but their reaction to this discomfort may be shaped by their attempts to balance strivings toward autonomy and relatedness. For example, an adolescent might feel needed as a peacemaker within the family and, as a consequence, inhibit his or her moves toward greater independence. Older or more autonomous adolescents may be less worried about the potential consequences of interparental hostility for their well-being and, therefore, less affected by their parents' discord. It is also possible that adolescent strivings for autonomy, particularly those marked by hostil- 
ity, could be a stimulus for conflict between parents. In the present study, we explored whether the degree of covariation between interparental hostility and adolescent hostile or facilitating responses in each interaction changed as the adolescent aged during the 2 years of the study.

\section{The Influence of Emotion Regulatory Capacities and Parenting Quality}

Aware of the variability across children in their reactions to interparental conflict, investigators have begun to explore factors that may shape a child's particular response. Coping theory and research (Lazarus \& Folkman, 1984) suggest that personal resources available to an individual, such as a sense of selfefficacy or temperamental strengths, are an important determinant of coping choices. Because exposure to interparental conflict may stimulate negative affect, it is especially important to consider the role of individual differences in children's capacities to regulate emotion (Crockenberg \& Langrock, 2001; Davies and Cummings, 1994; Maughan \& Cicchetti, 2002). Katz and Gottman (1995) have provided evidence that individual differences in parasympathetic nervous system reactivity (vagal tone), which may index emotion regulatory capacities, are linked with differential adaptation in the face of marital conflict. They found that children with low vagal tone showed a strong link between the amount of marital hostility displayed by their parents and subsequent displays of externalizing behavior, but no such link was present among children with high vagal tone. Kerig (1998) found that the ability to soothe oneself during interparental conflict protected girls from increased anxiety in the face of marital conflict. Other researchers have linked difficult temperament and aggressive personality traits, factors related to emotion regulatory abilities, to greater reactivity to interadult anger (Cummings et al., 1985; Easterbrooks et al., 1994).

In the present study, two dimensions of emotion regulation were examined as moderating factors that may help adolescents weather hostile marital behavior and reduce their tendency to respond to discord with negative family behaviors. The first dimension is the capacity to tolerate, experience, and acknowledge a range of affective states, which we refer to as Affective Tolerance. The second dimension focuses on the adolescent's ability to modulate his or her behavioral and expressive reactivity to negative emotional arousal, which we call Modulation of Emotional Expression. This latter dimension captures the capacity to control or modify one's expression of negative emotions to achieve personal and social goals (Schulz \& Lazarus, in press). Both of these dimensions have been cited in previous reviews of the literature as indicative of healthy emotion regulation (e.g., Cole, Michel, \& Teti, 1994).

We expected that variations in adolescents' capacities to tolerate negative affect and to modulate their emotional expression would be predictive of whether adolescents were more likely to respond to interparental discord with hostility or with positive engagement. More specifically, we hypothesized that stronger emotional regulatory capacities would be associated with less hostility and more positive engagement in the context of increased interparental hostility.

To understand fully the effects of marital conflict on children's behavior it is helpful to consider the influence of hostile parenting (Gordis, Margolin, \& John, 1997). Parentchild and interparental behaviors occur in the context of a complicated family system and both are likely to shape adolescents' own behavior in their families (e.g., Margolin, Gordis, \& John, 2001; McHale \& Cowan, 1996). Besides affecting children directly, marital hostility may influence children's behavior indirectly by "spilling over" into parenting (Erel \& Burman, 1995). In the current study, we examined whether hostile parenting in the context of the family interactions mediated yearyear links between marital hostility and adolescent behavior in these interactions.

The general emotional tone of parents' behavior toward the child may also shape (i.e., moderate) adolescents' responses to their parents' discord (Katz \& Gottman, 1997). Socialization theories (Bandura, 1977; Emery, 1982) suggest that marital and parenting behaviors serve as important models for 
children's social behavior both within and outside the family. Moreover, repeated exposure to hostile parenting may foster or heighten an adolescent's sense of emotional insecurity and thereby engender greater sensitivity to interparental conflict (Cummings, Davies, \& Campbell, 2000). In the current study, we hypothesized that adolescents whose parents were generally more hostile toward their children would be more likely to respond to interparental discord with more hostile and fewer constructive responses.

\section{Additional Sources of Variation in Adolescents' Responses to Interparental Conflict}

Previous studies suggest that the link between marital conflict and child behavioral difficulties is stronger in clinical samples than in community-based samples (Emery \& O'Leary, 1984; Jouriles et al., 1991; Reid \& Crisafulli, 1990). Although this elevated link may merely reflect the likelihood of increased behavior problems in samples that seek or are referred for treatment, it may also reflect vulnerabilities linked with psychopathology that may increase children's risk for problematic functioning in the face of marital conflict. Poor emotion regulatory abilities, which are a hallmark of a wide range of emotional and behavioral disorders, may be one of these vulnerabilities. Prior research and theory also suggest links between child psychopathology and particular responses to interparental conflict (Crockenberg \& Langrock, 2001; Davis et al., 1998). To clarify questions about the role of psychopathology, we explored links between interparental hostility and adolescents' behavior in a sample that was chosen to encompass a wide range of adolescent and family functioning. Half of the participants in our study were experiencing serious psychiatric difficulties at the start of the study, putting both the adolescents and their families under considerable strain. The sample for this study allows us to clarify the nature of interparental conflict/ child behavior links across the two groups and to compare the moderating impact of psychiatric background and a more specific vul- nerability factor (poor emotion regulatory capacities) on these links.

Both theory and prior research suggest that gender may influence children's responses to interparental conflict, but empirical findings in this area are inconsistent, and there is uncertainty about how children's age may influence any gender effects (Crockenberg \& Langrock, 2001; Fincham \& Grych, 2001; Osborne \& Fincham, 1996). Some have speculated that gender role socialization patterns may make it more likely that boys respond to interparental conflict with aggressive behavior and that girls respond with sadness or with attempts to repair the parental relationship (Davis et al., 1998). Although there is some evidence for this gender pattern in younger children (Cummings et al., 1985, 1989; Greene \& Anderson, 1999), the few studies examining this question in adolescence suggest the impact of gender may be different among older children. Cummings et al. (1991) found that adolescent girls displayed aggressive behavior patterns during family interactions to the same extent as adolescent boys. Davis et al. (1998) found that adolescent girls were as likely as adolescent boys to respond to interparental conflict with aggressive behaviors. In the current study, we explored the role of gender in shaping adolescents' constructive and aggressive responses to interparental conflict.

\section{Method}

\section{Participants}

Seventy-two two-parent families participated in the study. These families were drawn from the Adolescent and Family Development Project, a longitudinal study of psychological development (see details in Hauser, Powers, \& Noam, 1991). Adolescents were age 14-15 ( $M=14.6$ years) upon entering the study and were members of primarily Caucasian middleclass and upper middle-class families. Thirtyseven of these adolescents ( 21 girls, 16 boys) were recruited from the freshman class of a local high school, and 35 (19 girls, 16 boys) were recruited during an in-patient psychiatric hospitalization. The psychiatric group was drawn from consecutive early adolescent in- 
patient admissions to a psychiatric hospital. The predominant diagnoses of the hospitalized adolescents were mood or disruptive behavior disorders. The high school sample was selected from a larger group of volunteers to match the characteristics of the psychiatric sample with respect to age, gender, birth order, number of siblings, and whether one or two parents were living in the home (Hauser et al., 1991). The only demographic criterion on which the samples differed was socioeconomic status (higher for the high school sample). The adolescents in these 72 families are a subset of the adolescents from the 146 original families participating in the Adolescent and Family Development Project.

Given the current study's focus on interparental conflict, all adolescents living in single parent homes $(n=57)$ were excluded from the current study, leaving 89 eligible families. In 17 additional families, there was either only one parent present for all three of the family interactions required for this study or they did not participate at all in the family interaction component of the larger study. In the 72 remaining families, 59 of the families provided data in each of the three years of the study, eight families provided data in 2 of the years, and five families provided data in only 1 year. Parents were married in all 72 families, and all but two of these marriages remained intact across the 3 years of the study. The great majority of families included two biological parents. Sixteen percent of families in the high school group and $20 \%$ of families in the psychiatric group consisted of one biological parent and one step-parent. Analyses presented below used all available data. ${ }^{1}$

\section{Procedure}

Each year, when they were age 14,15 , and 16 , adolescents came to the laboratory for individ-

1. The main analyses for this paper used HLM, which makes effective use of all available data from each individual participant and from the sample as a whole to increase the reliability of parameter estimates at both the individual and sample levels (Raudenbush \& Bryk, 2002). For this reason, even the families with only 1 year of interaction data were included in the analyses. ual interviews, a family interaction task with their parents, and completion of questionnaires.

Adolescent semistructured interview. This semistructured 1-hr interview consisted of open-ended questions that probed for adolescents' descriptions of their current lives and past experiences, including relationships with parents and siblings, friendships, school, and other activities (Hauser, 1978). Adolescents were asked explicitly about how they managed the feelings that arose in each of these areas. Participants were interviewed by clinically trained interviewers (psychiatrists, psychologists, and social workers) who were blind to all other assessments of the adolescents (including the family interactions). Interviews were audiotaped and transcribed for later coding.

Family interaction task. Adolescents and their parents participated in a "revealed-differences" task (Strodtbeck, 1951) designed to present families with the challenge of acknowledging and discussing differences of opinion. Family members first completed a Kohlberg Moral Judgment Interview (Colby, Kohlberg, \& Candee, 1986) independently of one another. In this interview, specific moral dilemmas were presented in story form and the participant was asked to state his or her opinion about how the dilemma should be resolved. Two new dilemmas were presented each year to avoid tedium and repetition of answers. Each dilemma had structured follow-up questions linked with it. The family was then assembled so that they could be told about differences among family members in their responses to the Moral Judgment Interview. Three differences were presented in the following order: Mother and Adolescent versus Father, Father and Adolescent versus Mother, and Mother and Father versus Adolescent. For each difference, the family was instructed to take $10 \mathrm{~min}$ to defend their individual positions and then attempt to reach a consensus that represented the entire family. Presentation of these differences and the ensuing family discussions lasted for 40-45 min. Audiotapes of the family discussions were carefully transcribed for later coding (see Hauser, Powes, Naom, Jacobson, 
Weiss, \& Follansbee, 1984; Hauser et al., 1991, for more detailed description of the family procedure).

\section{Measures}

Adolescent behaviors toward parents, interparental hostility, and parenting hostility. The Constraining and Enabling Coding System (CECS; Allen et al., 1994; Hauser et al., 1984; Hauser, Powers, Weiss-Perry, Follansbee, Rajapark, Greene, Waters, Levine, \& Jurecic, 1992) was applied to transcripts of family interactions to measure adolescent hostile and facilitating behaviors toward parents, hostility between parents, and parents' hostility to their adolescent. This microanalytic coding system categorizes individual speech turns in terms of the extent to which they either interfere with (constrain) or facilitate (enable) family members discussing one another's thoughts and feelings. Coders note the source and target of the behavior/speech for each turn (adolescent to father, adolescent to mother, etc.) and the specific type of constraining or enabling behavior. If a speech turn is a particularly strong exemplar of the category being coded, it is assigned a score of 2 ; a score of 1 is assigned to typical exemplars of that code.

Hostility was indexed by combining CECS constraining codes for devaluing and judgmental. Speech coded as devaluing is characterized by belittling, criticism, mocking sarcasm, or derogatory or condescending language. Judgmental speech involves a punitive negative evaluation of another's ideas, feelings, or character. Particularly strong exemplars of judgmental speech are characterized by condemnatory global judgments of rightness and wrongness presented in a dogmatic and rejecting manner. For hostile speech to be coded as a strong examplar (2), it must be clearly insulting and antagonistic (e.g., "You would have to be an idiot to believe that") rather than merely insinuating hostility. To account for variability in the number of speech turns across families and to provide a meaningful metric we divided the total score for the relevant code by the total number of speech turns for that adolescent (or parent dyad). This transfor- mation results in a weighted percentage (recall that strong exemplars are coded as 2) of speech turns for that adolescent (or parent dyad) that were coded as hostile. In effect, scores were weighted to account for the intensity as well as the frequency of hostile speech turns (see Luborsky, 1998, for a similar weighting procedure). Adolescent Hostility was thus computed as the weighted percentage of adolescent-father and adolescent-mother speech turns that were hostile. Interparental Hostility was computed as the weighted percentage of mother-father and father-mother speech turns that were coded as hostile. Parenting Hostility was the weighted percentage of the mother's and father's speech turns to the adolescent that were coded as devaluing or judgmental. Adolescent Enabling, a measure of constructive engagement, was computed as the weighted percentage of total adolescent speech turns that were coded as explaining, focusing, problem solving, curiosity, acceptance, or active understanding.

Previous studies using these data have reported satisfactory interrater reliabilities for these codes (agreement for the hostility codes averaged $98 \%$ and for the facilitating codes $89 \%$ ) and provided evidence of construct and predictive validity (Allen et al., 1994; Hauser et al., 1984, 1991). For example, Allen and colleagues (1994) have shown that there were expectable linkages between parent and adolescent variables obtained from the CECS and macroanalytically coded family variables obtained from another family coding system, the Autonomy and Relatedness System.

As would be expected, adolescents in the present study whose speech turns were generally more hostile were less likely to display enabling speech than those who were generally less hostile, $r_{\mathrm{s}}(72)=-.46, p<.001$. Parents who generally displayed more hostility to their children were much more likely to have displayed hostility toward each other, $r_{\mathrm{s}}$ $(72)=.70, p<.001$. The magnitude of this between-family association points to the importance of examining the degree to which any within-family connections among interparental hostility and adolescent behavior across the 3 years of the study are independent of or mediated by parent-to-child hostility. 
Adolescent emotion regulatory capacities. The Haan (1977, 1993) Q-Sort of Defending and Coping Processes was used to code the transcripts of the adolescent open-ended interviews at ages 14,15 , and 16 . These interviews are distinct from the Moral Judgment Interviews described above. Coders who were blind to all other data sorted 60 descriptors into forced distributions with nine piles (from "most descriptive" to "least descriptive"). The average interrater reliability was .68 , indicating satisfactory reliability (Roston, Lee, \& Vaillant, 1992). Eighteen of the 60 descriptors in the Q-Sort were judged relevant to capturing two dimensions of adolescents' capacity to regulate emotion. Ten of the items described the capacity to experience and recall a range of negative feelings (e.g., unable to recall painful experiences, focuses attention on pleasant aspects of problems and ignores others, ignores aspects of situations that are potentially threatening [all reverse scored]). Eight of the items captured the ability to modulate emotional and behavioral reactions when challenged by difficulty or when experiencing distressing feelings (e.g., controls expression of affective reactions when not appropriate to express them, regulates expression of feelings proportionate to the situation, inhibits his/her reactions for the time being when appropriate). High internal consistency was obtained for both of these two scales ( $\alpha=$ $.94-.97$ over the 3 years of the study). A principal axis factor analysis at each time period of all 60 Q-Sort items yielded scales that were largely consistent with the rationally derived scales.

The 3-year average on each of the two scales was used in analyses to capture a reliable indicator of enduring differences in adolescents' capacities to regulate emotion. Use of these averages is supported by correlational analyses that indicated consistent betweenadolescent differences in emotion regulation across the 3 years of the study. Average correlations over the 3 years (i.e., Time 1 with Time 2 and with Time 3, and Time 2 with Time 3 ) were .58 for Affective Tolerance and .59 for Modulation of Emotional Expression. The correlation between Affect Tolerance and Modulation of Emotional Expression was $r(72)=.61, p<.01$, which indicates that these two emotion regulation scales share about $37 \%$ of their variance in common. The moderate degree of overlap suggests the importance of examining the scales simultaneously to determine the independent contribution of each to adolescent behaviors in the presence of interparental hostility.

Evidence for the validity of these scales is derived from their links to adolescents' psychiatric backgrounds and to the adolescents' typical (3-year average) enabling or hostile behavior in family interactions. Adolescents with psychiatric backgrounds were rated as having less tolerance for negative affect, $t(70)=7.67, p<.01$, and less ability to modulate their emotional expression, $t(70)=$ $8.47, p<.01$, than their high school peers. Modulation of emotion expression was significantly linked in the expected directions with adolescents' typical levels of facilitating behavior $\left(r_{\mathrm{s}}=.30, p=.01\right)$, and hostility $\left(r_{\mathrm{s}}=\right.$ $-.28, p=.02)$. Greater affective tolerance was linked with more overall facilitating behavior $\left(r_{\mathrm{s}}=.29, p=.02\right)$, and less overall hostile behavior, but the latter link was not significant $\left(r_{\mathrm{s}}=-.14, p=.25\right)$.

\section{Results}

Table 1 lists the means and standard deviations for the key study variables. As would be expected in a family problem-solving task, the devaluing and critical behaviors characteristic of hostile speech were generally in evidence at a much lower frequency than enabling (facilitating) behaviors. Coders identified at least some enabling behavior by the adolescents in all of the family interactions, and they noted some adolescent hostility toward their parents in $62 \%$ of the family interactions. The typical adolescent was rated as expressing hostility toward his or her parent in nearly one of every 20 speech turns. ${ }^{2}$ Parents were seen as display-

2. The weighted percentage was actually $5 \%$, but because speech turns that were strong exemplars of a category were weighted with a score of 2 in the coding system, the actual percentage of speech turns rated as hostile was less than $5 \%$. 
Table 1. Means and standard deviations of emotion regulatory capacities and family behaviors

\begin{tabular}{|c|c|c|c|c|c|c|c|c|c|c|c|}
\hline \multicolumn{4}{|c|}{$\begin{array}{c}\text { Emotion Regulation } \\
\text { Capacities } \\
(n=72)\end{array}$} & \multicolumn{8}{|c|}{$\begin{array}{l}\text { Family Behaviors } \\
(n=179-181)\end{array}$} \\
\hline \multicolumn{2}{|c|}{$\begin{array}{c}\text { Affect } \\
\text { Tolerance }\end{array}$} & \multicolumn{2}{|c|}{$\begin{array}{l}\text { Modulation } \\
\text { of Emotional } \\
\text { Expression }\end{array}$} & \multicolumn{2}{|c|}{$\begin{array}{l}\text { Adolescent } \\
\text { Enabling }\end{array}$} & \multicolumn{2}{|c|}{$\begin{array}{l}\text { Adolescent } \\
\text { Hostility }\end{array}$} & \multicolumn{2}{|c|}{$\begin{array}{c}\text { Interparental } \\
\text { Hostility }\end{array}$} & \multicolumn{2}{|c|}{$\begin{array}{l}\text { Parenting } \\
\text { Hostility }\end{array}$} \\
\hline Mean & $S D$ & Mean & $S D$ & Mean & $S D$ & Mean & $S D$ & Mean & $S D$ & Mean & $S D$ \\
\hline 5.57 & 1.77 & 4.79 & 1.27 & 1.29 & 0.22 & 0.05 & 0.07 & 0.05 & 0.07 & 0.03 & 0.03 \\
\hline
\end{tabular}

Note: Family behaviors are presented as the weighted proportion of total speech turns for the adolescent or couple that received the code in each category.

ing devaluing or critical behaviors toward their adolescent child in three quarters of the interactions and devaluing or critical behaviors toward each other in more than half of the interactions. The exchanges between some parents in these family interactions included a substantial percentage of hostility (the weighted percentages ranged as high as $37 \%$ ) and some adolescents were repeatedly hostile toward their parents (scores ranged as high as 54\%). A close look at the actual distributions for the Adolescent, Parenting and Interparental Hostility variables revealed classic Poisson distributions (see Breslow \& Clayton, 1993) that cannot be transformed to approximate normality. Hierarchical generalized linear modeling (HGLM) can be applied to Poisson distributions (Raudenbush \& Bryk, 2002; Raudenbush, Bryk, Cheong, \& Congdon, 2000) and was used in the principal analyses predicting hostile adolescent behavior. Because of the skewed distributions, Spearman rank correlations were used to examine zero-order, between-subjects associations with these variables.

There was a marginally significant difference in the percentage of enabling behavior displayed by the two groups of adolescents, $t(70)=1.92, p=.06$; on average, the high school group displayed a higher percentage of enabling behavior across the 2 years of the study than the psychiatric group. No significant differences were found between the two groups in the overall percentages of adolescent, interparental or parenting hostility. There were no gender differences in emotion regulatory capacities or in the overall percentages of adolescent and parental family behaviors.

Before investigating the within-family covariation of parental hostility and adolescent behavior across the 2 years of the study, we conducted more traditional betweensubjects correlational analyses (see Table 2). These analyses examined whether the children of couples who generally displayed more interparental or parent-to-child hostility generally showed more hostile or enabling behaviors during family interactions than the children of less hostile parents. To implement these analyses, we aggregated each family behavior score across the three interactions (by taking the mean) to obtain a reliable indicator of differences across families on each of these scales. Interparental and parent-to-child hostility were significantly correlated with adolescent hostility but not with adolescent enabling behaviors. Parents who generally displayed more hostility to each other or to their child were more likely than less hostile parents to have adolescents who generally displayed hostility toward the parents. 
Table 2. Spearman rank correlations between adolescent family behaviors and parents' hostile family behaviors $(N=72)$

\begin{tabular}{lcc}
\hline \hline $\begin{array}{c}\text { Adolescent } \\
\text { Behaviors }\end{array}$ & $\begin{array}{c}\text { Interparental } \\
\text { Hostility }\end{array}$ & $\begin{array}{c}\text { Parenting } \\
\text { Hostility }\end{array}$ \\
\hline Hostility & $.23^{*}$ & $.36^{* *}$ \\
Enabling & .04 & .14 \\
\hline \hline
\end{tabular}

$* * p<.01 . * p \leq .05$.

\section{Covariation of interparental hostility and adolescent behavior: Within-family multilevel analyses}

Covariation between adolescent behavior and interparental discord from interaction to interaction was examined using an HLM approach (Raudenbush \& Bryk, 2002). This approach permits simultaneous examination of within-family covariation (Level 1) of interparental conflict and adolescent behavior over the three time points and examination of between-family variation (Level 2) in the degree to which interparental conflict and adolescent behavior covary. Level 1 models provide estimates of covariation for each family. The Level 1 estimates for each family are then treated as dependent variables in the Level 2 equations to derive estimates of covariation for the sample as a whole. The maximum likelihood procedure used to estimate HLM models incorporates weighting algorithms that help to improve the precision of the estimated parameters for the sample as a whole (Kenny, Kashy, \& Bolger, 1998; Raudenbush \& Bryk, 2002).

The Level 1 model for adolescent hostility and interparental enabling behavior in each family can be written as

$$
\begin{aligned}
& \text { Adolescent Enabling } \text { Et }_{i t} \\
& \qquad \begin{aligned}
= & \pi_{0 i}+\pi_{1 i}(\text { Interparental Hostility })_{i t} \\
& +\pi_{2 i}(\text { year })+e_{i t} .
\end{aligned}
\end{aligned}
$$

Of particular interest is $\pi_{1 i}$, which is the expected increase in Adolescent $i$ 's enabling behavior associated with a unit increase in interparental hostility in Family $i$. Adolescent
Enabling $_{i t}$ is the adolescent's enabling behavior in Family $i$ 's interaction at time $t(t=1,2$, or 3 ). Individual differences across adolescents in their typical amount of enabling behavior in the family interactions are captured by $\pi_{0 i}$, and $e_{i t}$ represents unexplained variation in adolescent $i$ 's enabling at each time point. To account for linear changes in participants' behavior in the interaction tasks over the 3 years that might be related to developmental growth or practice effects associated with repeating similar family interaction tasks, year of the study $(1,2$, or 3$)$ was entered as a covariate in the Level 1 equation.

In HLM, the Level 1 parameters estimated for each family are pooled at Level 2 to obtain sample estimates. The slopes representing covariation between interparental hostility and adolescent enabling behaviors were allowed to vary randomly across families in the Level 2 model. This Level 2 equation can be written as

$$
\pi_{1 i}=\beta_{10}+r
$$

where $\beta_{10}$ represents the pooled estimate for the whole sample of covariation between interparental hostility and adolescent enabling behavior, and $r$ captures residual error. ${ }^{3}$

All model estimates were made using the HLM 5 computer program (version 5.04; Raudenbush et al., 2000). The models estimated for hostile adolescent family behaviors were identical to the enabling model with one exception. The distribution for hostile adolescent behaviors approximated a Poisson distribution commonly produced by count data, so the GLM extension of HLM (HGLM) for count data (see Breslow \& Clayton, 1993; Raudenbush et al., 2000, Raudenbush \& Bryk, 2002) was used to estimate these models. The coefficients estimated for adolescent hostile behaviors are presented in logged units so that the direction of change in adolescent hostile behavior associated with a 1-unit increase in in-

3. The slope capturing linear growth was viewed as a fixed effect at Level 2 because all the available degrees of freedom were already used by allowing the Level 1 intercept and interparental hostility parameter to vary randomly across families. 
Table 3. HLM estimates of within-family covariation between interparental hostility and adolescent family behavior over three discussions

\begin{tabular}{lccrr}
\hline \hline & \multicolumn{4}{c}{ Adolescent Behavior } \\
\cline { 2 - 5 } & $\beta_{10}$ & $S E$ & $t$ & $r_{\text {effect }}$ \\
\hline Model 1: adolescent hostility & & & & \\
$\quad$ Interparental hostility & $3.078^{*}$ & 1.250 & 2.46 & .28 \\
$\quad$ Year & -0.093 & 0.102 & -0.91 & -.07 \\
Model 2: adolescent enabling & & & & .20 \\
$\quad$ Interparental hostility & $0.331 \dagger$ & 0.189 & 1.75 & .07 \\
$\quad$ Year & 0.014 & 0.014 & 1.02 & .02 \\
\hline \hline
\end{tabular}

${ }^{a}$ Estimated coefficients for adolescent hostility are in logged units.

$* p=.01 . \dagger p<.1$.

terparental hostility can be easily interpreted (positive coefficients indicate increases in adolescent hostile behavior and negative coefficients indicate decreases).

HLM analyses summarized in Table 3 indicate that, in the years in which parents directed more hostile exchanges toward each other, their adolescent children were more hostile toward the parents than in years in which there was less interparental hostility. The adolescents also exhibited more enabling behaviors in the family discussions in which their parents exchanged more hostility, although this link was only marginally significant. The $t$ ratios, which are derived by dividing estimated parameters by their standard errors, can be converted to effect size correlations $\left(r_{\text {effect }}\right)$ to give a clearer indication of the magnitude of these associations (Karney \& Bradbury, 1997; Kurdek, 1998; O’Brien \& Peyton, 2002; Rosnow \& Rosenthal, 2002). The $r_{\text {effect }}$ of .28 for adolescent hostility represents a moderately strong effect while the $r_{\text {effect }}$ of .20 for adolescent enabling represents a smallmoderate effect (Cohen, 1988). These effects are impressive given the number of factors that might influence changes in adolescents' behaviors from year to year in these structured family interaction tasks. The analyses also indicated that there were no systematic developmental changes in the amount of hostility or enabling adolescents displayed across their adolescence. The parameters estimating linear changes in both of these adolescent be- haviors across the 2 years of the study were small and statistically insignificant.

\section{Direction of influence}

The results summarized in Table 3 indicate that there is covariation across the three interactions between interparental hostility and the two adolescent behaviors. They do not, however, indicate a direction of influence. Although we are particularly interested in the influence of interparental hostility on adolescent family behavior, it is possible that interparental hostility escalates in response to adolescent hostility and enabling behaviors. In an attempt to examine the direction of influence we conducted additional analyses. We split each interaction into two parts. Interparental hostility and adolescent hostility and enabling scores for each period were calculated. New HLM analyses were run in which interparental or adolescent behavior from the first part of each interaction was used to predict particular behaviors in the second part of the interaction after controlling for the behavior displayed in the first part of the interaction. Thus, for example, we investigated whether interparental hostility in the first part of the three interactions was linked with adolescent hostility in the second part of the three interactions after controlling for adolescent hostility in the first part of the interactions. None of the four models estimated (adolescent hostility or enabling in the second half as 
a function of interparental hostility in the first half, interparental hostility in the second half as a function of adolescent hostility or enabling in the first half) yielded significant results indicating that a consistent direction of influence was not present despite evidence of covariation.

\section{Developmental trends in the covariation of interparental hostility and adolescent behavior}

Although the results in Table 3 indicate that there was no linear developmental trend in adolescent enabling or hostile behaviors across the 2 years of the study, it is possible that the degree of covariation between interparental hostility and these adolescent behaviors changed as the adolescents got older. To investigate this possibility, we added an interaction term (Year in Study $\times$ Interparental Hostility) into the Level 1 HLM model (Equation 1) as an additional predictor. For the adolescent enabling model, the interaction term was not significant $(\beta=$ $-.02, p=.94)$ and for the adolescent hostility model it was significant $(\beta=-3.48, p=.04)$. The significant interaction term suggests that the link between adolescent and interparental hostility across the 2 years of adolescence depends, in part, on the age of the adolescent. As adolescents aged, they were less likely to show hostility in the discussions in which their parents also displayed hostility toward each other.

\section{Does parenting hostility mediate the within-family association between interparental hostility and adolescent behaviors?}

Particularly in the context of triadic family interactions, hostility between parents might be linked to children's behavior in part through its influence on parenting (e.g., Erel \& Burman, 1995). Parenting hostility may also have its own independent association with adolescent behavior. Because parenting hostility and interparental hostility were highly correlated at a between-family level in this study, it is important to examine whether the within-family covariation between interparental hostility and adolescent behavior over the 2 years of the study might be due to the independent or mediated influence of parenting hostility. To examine this question, we incorporated parenting hostility as an additional predictor into the Level 1 models described above (Equation 1). ${ }^{4}$ Parenting hostility did not have a statistically significant independent relationship with adolescent enabling $(\beta=-.85, p=.13)$ over and above the influence of interparental hostility and year in the study. Importantly, after accounting for the influence of parenting hostility, interparental hostility still covaried significantly with adolescent enabling across the 2 years of the study. Parenting hostility did have a significant, independent association $(\beta=14.70, p<.01)$ with adolescent hostility; that is, in years that parents displayed more hostility toward their child, the adolescent also displayed relatively more hostility toward the parents. After accounting for the influence of parenting hostility, interparental hostility no longer significantly covaried with adolescent hostility across the 2 years of the study. The latter finding suggests that parenting hostility may mediate the link between interparental and adolescent hostility and that it also has independent connections with adolescent hostility.

\section{Explaining variation across families in the link between interparental hostility and adolescent behavior}

Additional HLM analyses were conducted to examine individual- and family-based factors that might moderate the year-year relationship between interparental hostility and adolescents' family behavior. We were particularly interested in examining whether adolescents' emotional regulatory capacities were related to differences across families in the degree to which interparental hostility and adolescent behaviors covaried over the three discussions. Affective Tolerance and Modulation of Emotional Expression were added to the basic Level 2 model identified in Equation 2. Three additional variables were also incorporated into the Level 2 equation so that the effect of the

4. Parenting hostility was entered as a fixed effect. 
Table 4. HLM estimates of the moderating influence of emotion regulatory capacities, gender, psychiatric status, and parenting hostility on the covariation of interparental hostility and adolescent behavior

\begin{tabular}{|c|c|c|c|c|c|c|c|c|}
\hline & \multicolumn{4}{|c|}{ Model $1^{a}$} & \multicolumn{4}{|c|}{ Model 2} \\
\hline & $\beta$ & $S E$ & $t$ & $r_{\text {effect }}$ & $\beta$ & $S E$ & $t$ & $r_{\text {effect }}$ \\
\hline Affective tolerance & -0.611 & 0.800 & -0.77 & -.09 & $0.251 *$ & 0.131 & 1.92 & .23 \\
\hline $\begin{array}{l}\text { Modulation of } \\
\text { emot. expr. }\end{array}$ & $-2.130 *$ & 0.944 & -2.26 & -.27 & 0.176 & 0.170 & 1.03 & .13 \\
\hline Gender (female) & $6.119 * *$ & 2.005 & 3.05 & .29 & -0.398 & 0.324 & -1.23 & .15 \\
\hline Psychiatric status & -5.056 & 3.373 & -1.50 & -.18 & 0.616 & 0.528 & 1.17 & .14 \\
\hline Parenting hostility & $151.163 * *$ & 46.277 & 3.27 & .37 & $-12.22 \dagger$ & 6.584 & -1.86 & .22 \\
\hline
\end{tabular}

Note: Model 1, interparental hostility/adolescent hostility; Model 2, interparental hostility/adolescent overall enabling. ${ }^{a}$ Estimated coefficients for adolescent hostility are in logged units.

$* * p<.01 . * p \leq .05 . \dagger p<.1$.

emotional regulatory capacities was examined after controlling for the influence of parent-child hostility, psychiatric history, and gender. ${ }^{5}$ The 2 -year average in hostility directed by both mother and father toward the adolescent in the three family discussions was included in the Level 2 equation, as were dummy variables distinguishing the psychiatric sample from the high school sample $(1=$ psychiatric) and boys from girls $(1=$ girls $)$.

Results of these analyses are summarized in Table 4. As predicted, adolescent emotional regulatory abilities were related to the degree to which the adolescents showed more hostility or enabling behavior when their parents engaged in more hostile exchanges with each other. The two types of emotion regulatory capacities assessed had unique moderating effects. Adolescents who were rated by coders in independent interviews as being more able to modulate their emotional and behavioral reactions when challenged or distressed were

5. All of the Level 2 variables can be conceptualized as potential moderators of the connection between interparental hostility and adolescent behaviors. In fact, Equation 1 and the expanded Equation 2 can be combined algebraically into one equation that would include product terms (representing interactions between interparental hostility and each of the Level 2 predictors identified above) familiar to those who have investigated interactions in traditional regression-based approaches (see Raudenbush \& Bryk, 2002). less likely to display hostility during family interactions that were filled with greater interparental hostility. In contrast, adolescents seen as being more able to tolerate a range of emotions were more likely to engage positively (using enabling behaviors) in the family interaction task when their parents exchanged more hostile remarks with each other. The effect sizes of these associations approached a moderate level of strength as defined by Cohen (1988).

The analyses also indicated that adolescent gender and the typical level of hostility that parents displayed toward the adolescents were linked to variations in adolescents' behavior in the presence of interparental hostility. Girls were more likely than boys to display increased hostility in discussions in which there was greater interparental hostility. As anticipated, the adolescents whose parents were typically more hostile toward them displayed significantly more hostile behaviors and, at a trend level, fewer constructive behaviors when their mothers and fathers showed more hostility toward each other. Psychiatric history did not moderate the relationship within families between interparental hostility and adolescent behaviors; that is, after controlling for emotion regulatory abilities, hostile parenting and gender, adolescents in the psychiatric and nonpsychiatric groups did not differ in the extent to which their behaviors were linked with levels of interparental hostility. 


\section{Discussion}

This study examined the covariation of observed interparental hostility and adolescent behavior in families during three separate family interactions over a 2 -year period. As predicted, family interactions with more interparental hostility were accompanied by more expression of hostility toward parents by adolescents. More interparental hostility was also linked, at a trend level, with more attempts by adolescents to engage positively in the family's assigned task of discussing moral dilemmas. These linkages did not differ across the psychiatric and nonpsychiatric cohorts of adolescents in our sample, suggesting that we have identified a common pattern of adolescent behavior in the presence of interparental hostility that is robust across varying levels of psychological functioning.

Analyses directed at disentangling the direction of influence underlying the covariation between interparental hostility and adolescent behavior showed no consistent directional influence. This may reflect causal processes operating in both directions. It may also partly reflect methodological limitations that we discuss below. The findings do, however, indicate that adolescent hostile and facilitating behaviors changed in step with interparental hostility, which is consistent with past research suggesting that interparental conflict is emotionally disequilibrating and that behaviors enacted in its presence might be motivated by attempts to regulate this emotional strain (Crockenberg \& Forgays, 1996; Crockenberg \& Langrock, 2001; Davies \& Cummings, 1998). Hostile and positive engagement behaviors in the face of interparental hostility may serve similar functions for the adolescent. Adolescents who are knocked off balance emotionally by parents' discord might seek to regain a sense of emotional security by responding either with hostile actions that attempt to assert some control over the situation or with attempts to refocus the parents on the task at hand and thereby reduce the likelihood of further interparental discord.

The findings from this study indicate that emotion regulatory capacities may help determine whether adolescents use hostile or facil- itating responses in the presence of interparental discord. Compared with adolescents who were judged as less able to experience and acknowledge negative feelings, those who were seen as better able to tolerate a range of feeling states were more likely to show an increase in facilitating behaviors when interparental hostility increased.Adolescents who were judged as better able to modulate their emotional expression and behavior when experiencing negative feelings were less likely than adolescents with difficulties modulating their emotions to show increased hostility when their parents' behavior toward each other became more hostile. These findings are consistent with other empirical evidence that suggests that emotion regulatory abilities and related constructs, such as temperament or vagal tone, are linked with differential responses in the face of marital conflict (Cummings et al., 1985; Easterbrooks et al., 1994; Katz \& Gottman, 1995; Kerig, 1988; Maughan \& Cicchetti, 2002).

In our analyses, the degree of covariation between adolescent and interparental hostility depended, in part, on the age of the adolescent at the time of the family interactions. As the adolescents got older, they were less likely to display hostility in discussions in which their parents also displayed hostility toward each other. This developmental trend may reflect increasing emotion regulatory control over expression across adolescence (Grych \& CardozaFernandes, 2001) or it may reflect changes in the significance of marital discord for adolescents as they mature (Kerig, 2001). Older or more autonomous adolescents may be less worried about the potential consequences of the discord for their well-being and, therefore, less affected by their parents' conflict. It is also possible that increasing adolescent age and autonomy result in generally less reciprocity of behavioral exchanges within families.

As we expected, the quality of parent-tochild behavior also played an important role in predicting adolescent behaviors in the family interactions. Children who were generally exposed to more hostile parenting were significantly more likely to use hostile strategies and marginally less likely to use constructive strategies in the presence of interparental hostility. In this respect, overall parenting is a 
moderator of the covariation across time of marital hostility and adolescent behavior. These findings are consistent with theories of socialization that suggest that children with greater exposure to hostile behaviors come to see hostility as a viable mode of response (Bandura, 1977; Emery, 1982). The results are also consistent with the idea that repeated exposure to punitive parenting might exacerbate feelings of vulnerability fostered by exposure to interparental discord (Cummings et al., 2000; Gordis et al., 1997; Maughan \& Cicchetti, 2002). Children who are in a state of heightened vulnerability and who have been exposed to hostile role models may be more likely to take an aggressive path in attempting to restore their emotional security.

Variations within families in hostile parenting behavior from interaction to interaction were strongly linked with hostile but not constructive adolescent behaviors, over and above the influence of variations in interparental hostility. Analyses indicated that year-year changes in parenting hostility fully mediated the link between marital hostility and adolescent hostility but not between marital hostility and adolescents' constructive behaviors. The mediational results for adolescent hostility may reflect, in part, the idea that marital hostility is likely to spill over into parents' dealings with their adolescents, resulting in more hostile parenting (Erel \& Burman, 1995) and more aggressive adolescent behavior. These results may also reflect the possibility that hostility directed by parents at their children is more likely to be experienced by the children as a personal assault than witnessing marital discord, and is, therefore, more likely to elicit hostile responses.

Psychiatric background was not directly linked with variations in adolescents' behavior in the presence of interparental hostility, although it was clearly linked with differences in adolescents' overall emotion regulatory capacities. The stronger explanatory power of emotion regulatory capacities as compared to psychiatric history is of note, and may be due to two factors. First, the emotion regulatory variables used in this study may tap more psychologically meaningful and specific psychological processes than those captured by the fact of psychiatric hospitalization. Second, the predictive strength of our emotion regulatory variables may also be due to our rigorous measurement strategy of combining interviewbased assessments from three separate years to capture an enduring characteristic of the adolescents. In contrast, adolescents' psychiatric history may reflect a less stable marker of functioning. The links we found between adolescents' emotional regulatory capacities and their behaviors during family discussions are particularly noteworthy because of the independence of the methods and data sources from which these constructs were assessed. Interviews with the adolescents were rated using Q-sort methodology to obtain the measures of emotion regulatory capacities, and careful coding of yearly family interactions yielded ratings of parent and adolescent behaviors.

The specificity of the moderating effects of the two emotion regulatory variables provides support for considering affect tolerance and modulation of emotion expression as separate dimensions of emotion regulation, despite their high degree of correlational overlap. When confronted with emotional situations, adolescents regulate their emotions in an attempt to pursue their personal goals (Schulz \& Lazarus, in press). In the context of hostile family interactions, these goals are likely to include the preservation of emotional security (Davies \& Cummings, 1994). The moderating effects of the emotion regulatory capacities in this study are consistent with the notion that interparental hostility is emotionally disequilibrating for adolescents. When faced with an emotionally challenging situation, greater comfort experiencing a range of affective states may give adolescents access to a broader repertoire of coping strategies and allow them to remain engaged with others in positive ways (Dodge, 1991). The ability to modulate behavioral and expressive reactions associated with negative emotional arousal may be necessary to inhibit an impulsive tendency to react to interparental conflict with an aggressive response.

The relatively few studies that have investigated gender differences in adolescent responses to marital discord indicate that, at this 
age, girls may be at least as likely as boys to respond to interparental conflict with hostile behaviors (Cummings et al., 1991; Davis et al., 1998). We found that girls were actually more likely than boys to display increased hostility in the presence of increased interparental conflict. The effect size of this gender difference was moderate in magnitude, suggesting that this difference between boys and girls is meaningful. Further research is warranted to clarify the extent and nature of these gender differences. Several investigators have suggested that one route to greater clarity about the role of gender is to consider both the gender of the child and the gender of the parent who is the primary instigator of marital conflict (Crockenberg \& Langrock, 2001; Osborne \& Fincham, 1996).

It is impossible from these data to be clear about the direction of effects; that is, the extent to which adolescent behaviors influenced or were influenced by interparental hostility. It is certainly plausible that parents' hostility toward each other may be stimulated by an adolescent's hostility. However, it is difficult to construct a plausible scenario in which parents' hostility toward each other would escalate in response to increases in their child's facilitating behaviors. Thus, in the case of facilitating behaviors, one direction of influence seems more likely than the other.

Detailed sequential analysis of family interactions (e.g., Davis et al., 1998) can provide additional information about the temporal patterns of adolescent and parental behaviors. However, such microlevel analyses are not possible when examining a behavior that has a relatively low base rate. In our study, the low base rate of interparental hostility restricted us to a relatively coarse mode of examining sequences (i.e., dividing each family interaction into two parts). Even when base rates are higher, the private languages and hidden meanings that exist within any family and the complexity of family interactions may make it challenging to ascertain the "real" direction of influence. For example, a seemingly innocuous comment or shrug of a shoulder by a parent might be perceived as hostile by an adolescent but not coded as hostile by outside observers.
Because the same coders were responsible for rating all of the behaviors in the family interactions, it is important to consider the possibility that method artifacts in our research design inflated the links that emerged between interparental hostility and adolescent behavior. For example, coders might not differentiate the behaviors of specific family members from the overall tone of the family's interaction. There are two reasons why we do not think such method artifacts underlie the central findings of this study. First, at the within-family level, interparental hostility was positively linked with two distinct and oppositely valenced adolescent behaviors: hostility and positive engagement. Second, if method artifacts were driving our findings we would have found consistent and strong associations between interparental hostility and adolescent behaviors at the between-family level. Adolescent enabling was not correlated with interparental hostility and the connection between adolescent and interparental hostility was quite modest. There was, however, a strong betweensubjects link between parent-to-child hostility and interparental hostility. Shared method variance may have inflated this link.

It is also important to note the challenges inherent in measuring emotion regulation abilities. Adolescents vary in their ability and willingness to label their emotional reactions and to discuss emotionally salient aspects of their lives. Self-report measures of emotion regulation are particularly vulnerable to distortions linked to such individual variation but observer ratings like the ones used in this study may also be influenced by these differences. Nevertheless, we believe the results of this study suggest that combining sensitive semistructured interviews and careful observational coding is an effective strategy for assessing meaningful differences in emotion regulation abilities.

An important strength of this study is the observation of adolescents exposed to conflict between their parents rather than between strangers. Capturing adolescents' behaviors when exposed to their parents' discord is likely to provide information that cannot be obtained from analog studies that use simulated conflict. A second major strength is 
the inclusion of observations from family interactions conducted at three points in time. Repeated observations allowed us to examine within-family covariation between interparental and adolescent behaviors, and in this way, to focus specifically on potential short-term mechanisms linking these behaviors within each interaction. Compared with typical crosssectional studies examining families at one point in time, repeated family observations and examination of within-family covariation is a labor-intensive research strategy. Without this focus on repeated interactions, however, important information about the linkages between interparental conflict and adolescent behavior may be lost. When we conducted traditional between-subjects analyses comparing the adolescents of generally more hostile couples with adolescents of less hostile couples, we found no evidence of a link to the frequency of adolescents' constructive behaviors in the family tasks. Only when we conducted within-family analyses of repeated interactions did we find connections between interparental hostility and constructive adolescent behavior.

Differences in the pattern of within-family links compared to between-family links help narrow the field of likely mechanisms that shape adolescents' behavior in the presence of marital discord. Connections between adolescent behavior and marital behavior at the betweenfamily level could be due to a number of relatively long-acting or stable factors such as long-term parental socialization effects or common genetic origins of personality or behavioral styles. The presence of significant associations at the within-family level can only be explained by shorter term mechanisms that account for yearly fluctuations in adolescent behavior. Emotional disequilibration linked to fluctuations in interparental hostility across the three interactions is one plausible mechanism. In future research, the combination of withinfamily and between-family perspectives may help to refine further our understanding of the empirical connection between marital conflict and child behavior.

\section{References}

Allen, J. P., Hauser, S. T., Bell, K. L., \& O'Connor, T. G. (1994). Longitudinal assessment of autonomy and relatedness in adolescent-family interactions as predictors of adolescent ego development and self-esteem. Child Development, 65, 179-194.

Allen, J. P., Kuperminc, G. P., \& Moore, C. M. (1997). Developmental approaches to understanding adolescent deviance. In S. S. Luthar, J. A. Burack, D. Cicchetti, \& J. Weisz (Eds.), Developmental psychopathology: Perspectives on risk and disorder (pp. 548567). Cambridge: Cambridge University Press.

Amato, P. R. \& Keith, B. (1991). Parental divorce and the well-being of children: A meta-analysis. Psychological Bulletin, 110, 26-46.

Bandura, A. (1977). Social learning theory. Englewood Cliffs, NJ: Prentice-Hall.

Breslow, N., \& Clayton, D. G. (1993). Approximate inference in generalized linear mixed models. Journal of the American Statistical Association, 88, 9-25.

Cairns, R. B., Bergman, L. R., \& Kagan, J. (Eds.). (1998). Methods and models for studying the individual. Thousand Oaks, CA: Sage.

Cohen, J. (1988). Statistical power analysis for the behavioral sciences. Hillsdale, NJ: Erlbaum.

Colby, A., Kohlberg, L., \& Candee, D. (1986). Assessing moral judgements: A Manual. New York: Cambridge University Press.

Cole, P. M., Michel, M. K., \& Teti, L. O. D. (1994). The development of emotion regulation and dysregulation: A clinical perspective. In N. A. Fox (Ed.), The development of emotion regulation: Biological and behavioral considerations (Vol. 59, pp. 73-100). Chicago: University of Chicago Press.

Crockenberg, S., \& Forgays, D. K. (1996). The role of emotion in children's understanding and emotional reactions to marital conflict. Merrill-Palmer Quarterly, 42, 22-47.

Crockenberg, S., \& Langrock, A. (2001). The role of emotion and emotional regulation in children's responses to interparental conflict. In J. H. Grych \& F. D. Fincham (Eds.), Interpersonal conflict and child development: Theory, research and application ( $\mathrm{pp}$. 129-156). New York: Cambridge University Press.

Cummings, E. M. (1987). Coping with background anger in early childhood. Child Development, 58, 976-984.

Cummings, E. M., Ballard, M., \& El-Sheikh, M. (1991). Response of children and adolescents to interadult anger as a function of gender, age, and mode of expression. Merrill-Palmer Quarterly, 37, 543-560.

Cummings, E. M., Davies, P. T., \& Campbell, S. B. (2000). Developmental psychopathology and family process: Theory, research, and clinical implications. New York: Guilford Press.

Cummings, E. M., Iannotti, R., \& Zahn-Waxler, C. (1985). The influence of conflict between adults on the emotions and aggression of young children. Developmental Psychology, 21, 495-507.

Cummings, E. M., Simpson, K. S., \& Wilson, A. (1993). Children's responses to interadult anger as a function of information about resolution. Developmental Psychology, 29, 978-985. 
Cummings, E. M., Vogel, D., Cummings, J., \& El-Sheikh, M. (1989). Children's responses to different forms of expression of anger between adults. Child Development, 60, 1392-1404.

Davies, P. T., \& Cummings, E. M. (1994). Marital conflict and child adjustment: An emotional security hypothesis. Psychological Bulletin, 116, 387-411.

Davies, P. T., \& Cummings, E. M. (1998). Exploring children's emotional security as a mediator of the link between marital relations and child adjustment. Child Development, 69, 124-139.

Davies, P. T., \& Forman, E. M. (2002). Children's patterns of preserving emotional security in the interparental subsystem. Child Development, 73, 1880-1903

Davies, P. T., Myers, R. L., \& Cummings, E. M. (1996). Responses of children and adolescents to marital conflict scenarios as a function of the emotionality of conflict endings. Merrill-Palmer Quarterly, 42, 1-21.

Davies, P. T., Myers, R. L., Cummings, E. M., \& Heindel, S. (1999). Adult conflict history and children's subsequent responses to conflict: An experimental test. Journal of Family Psychology, 13, 610-628.

Davis, B. T., Hops, H., Alpert, A., \& Sheeber, L. (1998). Child responses to parental conflict and their effect on adjustment: A study of triadic relations. Journal of Family Psychology, 12, 163-177.

Dodge, K. A. (1991). Emotion and social information processing. In J. Garber \& K. A. Dodge (Eds.), The development of emotion regulation and dysregulation (pp. 159-181). New York: Cambridge University Press.

Easterbrooks, M. A., Cummings, E. M., \& Emde, R. N. (1994). Young children's responses to constructive marital disputes. Journal of Family Psychology, 8, 160-176.

El-Sheikh, M., Harger, J., \& Whitson, S. M. (2001). Exposure to interparental conflict and children's adjustment and physical health: The moderating role of vagal tone. Child Development, 72.

Emery, R. E. (1982). Interparental conflict and the children of discord and divorce. Psychological Bulletin, 29, 310-330.

Emery, R. E., \& O’Leary, K. D. (1984). Marital discord and child behavior problems in a nonclinic sample. Journal of Abnormal Child Psychology, 12, 411-420.

Erel, O., \& Burman, B. (1995). Interrelatedness of marital relations and parent-child relations: A metaanalytic review. Psychological Bulletin, 118, 108-132.

Fincham, F. D., \& Grych, J. H. (2001). Advancing understanding of the association between interparental conflict and child development. In J. H. Grych \& F. D. Fincham (Eds.), Interparental conflict and child development: Theory, research, and application (pp.443451). New York: Cambridge University Press.

Gordis, E. B., Margolin, G., \& John, R. S. (1997). Marital aggression, observed parental hostility and child behavior during triadic family interaction. Journal of Family Psychology, 11, 76-89.

Greene, S. M., \& Anderson, E. R. (1999). Observed negativity in large family systems: Incidents and reactions. Journal of Family Psychology, 13, 372-392.

Grych, J., \& Cardoza-Fernandes, S. (2001). Understanding the impact of interparental conflict on children: The role of social cognitive processes. In J. H. Grych \& F. D. Fincham (Eds.), Interparental conflict and child development: Theory, research, and application (pp. 157-187). New York: Cambridge University Press.
Grych, J. H., \& Fincham, F. D. (1990). Marital conflict and children's adjustment: A cognitive-contextual framework. Psychological Bulletin, 108, 267-290.

Grych, J. H., \& Fincham, F. D. (1993). Children's appraisals of marital conflict: Initial investigations of the cognitive-contextual framework. Child Development, 64, 215-230.

Haan, N. (1977). Coping and defending: Processes of selfenvironment organization. New York: Academic Press.

Haan, N. (1993). The assessment of coping, defense, and stress. In L. Goldberger \& S. Breznitz (Ed.), Handbook of stress: Theoretical and clinical aspects (2nd ed, pp. 258-273). New York: Free Press.

Hauser, S. T. (1978). Semi-structured interview for adolescents: Unpublished manuscript, Harvard Medical School.

Hauser, S. T., Powers, S. I., \& Noam, G. (1991). Adolescents and their families: Paths of ego development. New York: Free Press.

Hauser, S. T., Powers, S., Noam, G., Jacobson, A. M. Weiss, B., \& Follansbee, D. (1984). Familial contexts of adolescent ego development. Child Development, $55,195-213$.

Hauser, S. T., Powers, S. I., Weiss-Perry, B., Follansbee, D., Rajapark, D. C., Greene, W. M., Waters, P. L., Levine, H., \& Jurecic, L. (1992). Constraining and enabling coding system. Unpublished manuscript, Harvard Medical School.

Jenkins, J. M., Smith, M. A., \& Graham, P. J. (1989). Coping with parental quarrels. Journal of the American Academy of Child and Adolescent Psychiatry, 28, 182-189.

Jouriles, E. N., Bourg, W., \& Farris, A. M. (1991). Marital adjustment and child conduct problems: A comparison of the correlation across subsamples. Journal of Consulting and Clinical Psychology, 59, 354-357.

Karney, B. R., \& Bradbury, T. N. (1997). Neuroticism, marital interaction, and the trajectory of marital satisfaction. Journal of Personality and Social Psychology, 64, 221-242.

Katz, L. F., \& Gottman, J. M. (1995). Vagal tone protects children from marital conflict. Development and Psychopathology, 7, 83-92.

Katz, L. F., \& Gottman, J. M. (1997). Buffering children from marital conflict and dissolution. Journal of Clinical Child Psychology, 26, 157-171.

Kenny, D. A., Kashy, D. A., \& Bolger, N. (1998). Quantitative methods in social psychology. In D. Gilbert, S. Fiske, \& G. Lindzey (Eds.), Handbook of social psychology (4th ed., pp. 233-265). New York: McGraw-Hill.

Kerig, P. K. (1998). Moderators and mediators of the effects of interparental conflict on children's adjustment. Journal of Abnormal Child Psychology, 26, 199-212.

Kerig, P. K. (2001). Children's coping with interparental conflict. In J. H. Grych \& F. D. Fincham (Eds.), Interparental conflict and child development: Theory, research, and application (pp. 213-245). New York: Cambridge University Press.

Kurdek, L. A. (1998). The nature and predictors of the trajectory of change in marital quality over the first four years of marriage for first-married husbands and wives. Journal of Family Psychology, 12, 56-65.

Lazarus, R. S., \& Folkman, S. (1984). Stress, appraisal, and coping. New York: Springer.

Luborsky, L. (1998) A guide to the CCRT Method. In L. Luborsky \& P. Crits-Christoph (Eds.), Understand- 
ing transference: The core conflictual relationship theme method (2nd ed., pp. 15-54). Washington, DC: American Psychological Association.

Magnusson, D. (1998). The logic and implications of a person-oriented approach. In R. B. Cairns, L. R. Bergman, \& J. Kagan (Eds.), Methods and models for studying the individual (pp. 33-64). Thousand Oaks, CA: Sage.

Margolin, G., Gordis, G. E. B., \& John, R. S. (2001). Coparenting: A link between marital conflict and parenting in two-parent families. Journal of Family Psychology 15, 3-21.

Maughan, A., \& Cicchetti, D. (2002). Impact of child maltreatment and interadult violence on children's emotion regulatory abilities and socioemotional adjustment. Child Development, 73, 1525-1542.

McHale, J. P. \& Cowan, P. A.(Eds.). (1996). Understanding how family-level dynamics affect children's development: Studies of two-parent families. New directions for child development. San Francisco, CA: Jossey-Bass.

Nesselroade, J. R. (2001). Intraindividual variability in development within and between individuals. European Psychologist, 6, 187-193.

O'Brien, M., \& Peyton, V. (2002). Parenting attitudes and marital intimacy: A longitudinal analysis. Journal of Family Psychology, 16, 118-127.

Osborne, L. N., \& Fincham, F. (1996). Marital conflict, parent-child relationships, and child adjustment: Does gender matter? Merrill-Palmer Quarterly, 42, $48-75$.

Patterson, G. R., \& Reid, J. B. (1984). Social interactional processes within the family: The study of the moment- by-moment family transactions in which human social development is embedded. Journal of Applied Developmental Psychology, 5, 237-262.

Raudenbush, S. W., \& Bryk, A. S. (2002). Hierarchical linear models (2nd ed.). Thousand Oaks, CA: Sage.

Raudenbush, S. W., Bryk, A. S., Cheong, Y. F., \& Congdon, R. T. (2000). HLM 5: Hierarchical linear and nonlinear modeling. Lincolnwood, IL: Scientific Software.

Reid, W. J., \& Crisafulli, A. (1990). Marital discord and child behavior problems: A meta-analysis. Journal of Abnormal Child Psychology, 18, 105-117.

Rosnow, R. L., \& Rosenthal, R. (2002). Beginning behavioral research (4th ed.). Upper Saddle River, NJ: Prentice.

Roston, D., Lee, K. A., \& Vaillant, G. E. (1992). A q-sort approach to identifying defenses. In G. E. Vaillant (Ed.), Ego mechanisms of defense: A guide for clinicians and researchers (pp. 217-233). Washington, DC: American Psychiatric Press.

Schulz, M. S., \& Lazarus, R. S. (in press). Emotion regulation during adolescence: A cognitive-mediational conceptualization. In A. M. Cauce \& S. T. Hauser (Eds.), Adolescence and beyond: Family interactions and transitions to adulthood; Advances in Family Research. Mahwah, NJ: Erlbaum.

Strodtbeck, F. (1951). Husband-wife interaction over revealed differences. American Sociology Review, 16, 463-473.

Wallerstein, J. S., \& Blakeslee, S. (1989). Second chances: Men, women, and children a decade after divorce. New York: Tichnor \& Fields. 